\title{
PEDAGOGY
}

\section{Aligning Critical Physical Education Teacher Education and Models-Based Practice}

\author{
Glenn Fyall and Michael W. Metzler
}

\begin{abstract}
In 1999, the New Zealand government released a new Health and Physical Education (HPE) curriculum that reflected a fundamental shift from the traditional and dominant skill mastery approach. The "new" HPE curriculum was based on humanistic principles and supported by constructivist notions of teaching and learning, within a critical pedagogy. Since this time, and a subsequent curriculum revision in 2007, the HPE curriculum writers have suggested that physical education (PE) teachers and physical education teacher education (PETE) students in New Zealand have struggled to understand the epistemological complexities and pedagogical implications of critical pedagogy in their practice. Therefore, this paper highlights the findings of a study that explored a New Zealand PETE program, in light of HPE within the New Zealand Curriculum (NZC). Additionally, and in light of the findings, the authors consider an examination of Kirk's (2013) concept of models-based practice as it could apply to the preparation and professional development of physical education teachers in New Zealand. The case study included nine volunteer participants, from a cohort of 32 students, who were nearing graduation from a critically

Glenn Fyall is a lecturer in Physical Education and Sport Curriculum and Pedagogy, College of Education, Health and Human Development, The University of Canterbury, Christchurch, New Zealand. Michael W. Metzler is a professor (emeritus) and associate director, Center for Excellence in Teaching and Learning, Georgia State University. Please send author correspondence to glenn.fyall@canterbury.ac.nz
\end{abstract}


oriented PETE program in New Zealand. Semistructured interviews were deployed and analyzed and reoccurring themes central to the purpose of the study identified and explored. The participants viewed movement contexts as being pivotal for learning in physical education and that the NZC had multiple educational aims and purposes. Participants also believed that PE teachers were required to move beyond direct instruction and implement a variety of teaching styles to achieve these multiple aims. However, the participants also shared misunderstandings and paradigmatic uncertainty around the critical and humanistic underpinnings of the NZC and failed to demonstrate an understanding of how this is enacted through critical pedagogy. The implications of this theory to practice nexus are further discussed in light of recent research debate around models-based practice.

Physical education (PE) has no essential transcendental characteristics. Since the historical records show it has changed over time, how then can we avoid the position at the other extreme, that it has no meaning at all, at least, only the meaning that we arbitrarily select or choose to give it? (Kirk, 2010, p. 11)

In the latter part of 20th century, teachers, teacher educators, and scholars keenly debated what they believed to be the content and curricula of PE and physical education teacher education (PETE). Unfortunately, the debate largely remained unresolved (Fernandez-Balboa, Barrett, Solomon, \& Silverman, 1996). However, some consensus emerged, suggesting that "movement" is fundamental to any description or conceptualization of PE (e.g., Jewett, Bain, \& Ennis, 1995). Fernandez-Balboa et al. (1996) stated that "although we agree that movement is the common thread of our content, many of the shapes that content has taken may not be appropriate" (p. 54). Today, there is general agreement that movement is an appropriate context for $\mathrm{PE}$, but a growing number of physical educators believe that PE curricular, defined by movement and the acquisition of physical skills alone, may reduce it to mere physical activity with little educative value (Culpan \& Bruce, 2007; Fyall, 2017; Philpot, 2016; Philpot \& Smith, 2011).

Siedentop and Tannehill (2000) suggested that curricular models are founded on assumptions. These assumptions include identifying 
the educational needs of a community or society. Intuitively, the educational community or societal needs will be influenced socially and culturally and therefore will be interpreted in a variety of ways. For example, in the United States, Metzler, McKenzie, van der Mars, Barrett-Williams, and Ellis (2013) promote the Health Optimizing Physical Education curriculum model, highlighting the need "for children and youths to be more physically active and more regularly engaged in other healthy behaviors" (p. 42). The justification by Metzler et al. (2013), to emphasize health promotion in the PE curriculum, was founded on evidence-based, public health needs.

In the context of this study, in Aotearoa New Zealand during the 1990s, PE curriculum writers considered and advocated for-or in Kirk's (2010) words, "arbitrarily selected” (p. 11) - PE content and aligned pedagogies that drew from the critical and humanistic paradigms (Gillespie \& Culpan, 2000). In this sense, the New Zealand Curriculum (NZC) writers interpreted a physically educated person from a sociocultural perspective, where physical contexts provided the backdrop for learning "in, through and about movement" (Culpan \& Bruce, 2007, p. 6). Most notably, the NZC architects considered the work of Freire (1970), Giroux (1983), Kirk (1988), Tinning (1991), Lawson (1992), Sage (1993), van Holst, (1993), Jewett (1994), McLaren (1995), and Fernandez-Balboa (1997a), who promoted critical pedagogy (CP) in $\mathrm{PE}$, as an alternative to existing Western political and educational philosophy (Culpan, 2004; Culpan \& Bruce, 2007).

Consequently, in 1999, after significant educational debate and political contestation, the New Zealand government released a radically different Health and Physical Education (HPE) curriculum. Fundamentally, the principles and objectives of this document reflected a shift from the entrenched skill mastery approach, supported by technocratic perspectives of teaching and learning (Tinning, 1991), to one that was informed by notions of humanism and CP. The concept of CP was aligned with and supported by constructivist perspectives of teaching and learning (Culpan \& Bruce, 2007; Ministry of Education, 1999, 2007).

Culpan (2004), one of the curriculum writers, suggested that leading up to its release, "the major critique [of HPENZC] was The Education Forum, a select group of conservative school principals, 
with strong affiliations to the New Zealand Business Round Table (prominent businesspeople with strong new right views)" (p. 238). Culpan (2004) proposed that the Education Forum's (EF, 1998) critique included the suggestion that health and $\mathrm{PE}$ should be restricted "to a traditional paradigm of skills development" (p. 239). Culpan (2004) also promoted that the notion of student-centeredness had epistemologically and pedagogically challenged the EF's conception of teaching and learning, as, in their view, the teacher was necessarily the focal point of the teaching and learning process. In the EF's (1998) view, teachers are professionally equipped in knowledge and procedures and are capable of making effective pedagogical decisions in the best interest of the individual learner. This perspective considers that effective student-centered teaching identifies the learners different modes of learning and consequently implements a variety of teaching styles appropriate to the learner's needs. This is evidenced in the following excerpts from the EF's (1998) submission on the draft curriculum:

Far from recognizing its fallibility, the draft elevates the "needs" notion to the prime determinant of a needs-based curriculum poised on the principle of student-centeredness... a consequence of this needs-based approach is the significant side-lining of the work of the teacher to that of facilitator ... the notion of student-centered learning is woolly, imprecise, unanalysed and undefended. (EF, 1998, p. 33)

Additionally, theEFdismissed the concept of student-centeredness as promoted in the draft curriculum, and recommended to the government that it

... reject the notion of child-centeredness as promoted within the draft ... [and] note that there is a more academically credible and rigorous "student-centered" approach which seeks to identify differences in modes of learning and consequently in effective teaching styles, maintains the importance of knowledge and disciplinary procedures, upholds the need for teachers who are authorities in both content and procedures. (p. 38) 
In the context of this paper, this point will be discussed further in subsequent sections, but it is worthy of mention that the release and subsequent implementation of the NZC has raised many concerns about the epistemological and pedagogical challenges now presented to physical educators in New Zealand (e.g., Barker, 2008; Burrows, 2005).

More recently, growing evidence in New Zealand suggests that PE teachers and PETE students may struggle to understand the pedagogical complexities of PE within the NZC and the implementation of its critical foundations through a critical pedagogy (Fyall, 2016, 2017; Philpot, 2016; Philpott \& Smith, 2011).

\section{Critical Pedagogy}

$\mathrm{CP}$ arises from the need to create an environment where conscientization can occur and where social and cultural inequities can be exposed (Freire, 1970). The evolution of CP from critical theory consistently demonstrates a passion for devolving hierarchy and power inequity within an educational setting and a will for promoting social change (Fernandez-Balboa, 1997b; Freire, 1970; Giroux, 1983; Kincheloe, 2008; McLaren, 1995). Gur-Ze'ev (n.d.) accurately described this as

a critical dialogue between educators and educated that (are) committed to demolishing hierarchies and power relations, within which students are empowered (ideally) to the degree of being able to decipher the hidden codes, power relations, and manipulations that build and represent reality, knowledge and identities. (“Critical Theory's Critiques," para. 6)

Culpan and Bruce (2007) described CP, as it is intended for PE within the NZC, as emancipatory and empowering. It is emancipatory in the sense that $\mathrm{CP}$ "enables people to obtain the knowledge, skills and power necessary to gain a greater degree of control over their individual and collective lives" (Culpan \& Bruce, 2007, p. 3). It is empowering, enabling individuals and groups to identify hegemonic practices and take action to promote social change.

Essential, then, to the educational success of $\mathrm{CP}$ is providing students with an appropriate environment and accompanying learning opportunities that promote critical thinking, questioning, and 
discussion within a power neutral classroom (Macdonald, 2003). Similarly, Culpan and Bruce (2007) proposed that critical thinking, within the NZC, requires teachers to consider this not only as a process of problem solving and questioning that promote higher order thinking skills, but also as an examination and questioning of educational assumptions, inequality, and hegemony in a social, political, and historical sense. Intuitively, and in the context of the NZC, where students are required to examine, question, evaluate, and challenge taken-for-granted assumptions about issues and practices (Ministry of Education, 1999, 2007), it is expected that teachers are capable of designing and implementing student learning opportunities that promote these outcomes. However, as some have suggested, this provides significant pedagogical and epistemological challenges to many PE teachers in New Zealand (Barker, 2008; Burrows, 2005; Culpan, 2008). Specifically, as Culpan (2008) outlines, it appears that PE teachers in New Zealand struggle to align curricular aims with appropriate epistemological decisions and pedagogical strategies. Therefore, the pedagogical approaches of physical educators in New Zealand schools generally do not reflect the principles and objectives of the NZC.

Many have argued that the challenges facing advocates of $\mathrm{CP}$ are far larger than teachers and students merely embracing epistemological and pedagogical change; they are far more deeply rooted concerns (Ennis, 1997; Kincheloe, 2008; O'Sullivan, Siedentop, and Locke, 1992; Sicilia-Camacho \& Fernandez-Balboa, 2009; Tinning, 2002). Kincheloe (2008) encapsulated this, suggesting that critical pedagogues are continually challenged by "competing ethical claims" and "institutional morality" and that educational sites are not "neutral" sites waiting to be shaped by educational professionals:

Although such professionals do possess agency ... these contexts are shaped in the same way language and knowledge are constructed, as historical power makes particular practices seem natural-as if they could have been constructed in no other way. (Kincheloe, 2008, p. 1)

In this sense, the authors suggest that those advocating for critical perspectives within education may be seen as counterproductive to their intended aims because they attack the hierarchies, values, and 
beliefs of traditional educational settings. It is suggested that those subscribing to traditional educational settings, where entrenched teacher-centered perspectives dominate, find critical perspectives challenging (Ennis, 1997; Fernandez-Balboa, 1997b; Tinning, 2002). In this belief, it is suggested that critical pedagogues assume a position of moral superiority and are often criticized and alienated for it (Sicilia-Camacho \& Fernandez-Balboa, 2009). Therefore, the authors propose that it is futile to conclude that critical pedagogues cannot be part of or affected by the values, beliefs, and agendas of the dominant culture and that it would be just as futile to suggest that education, and therefore PE, is not bound and influenced by the same dominant cultural assumptions.

Sicilia-Camacho and Fernandez-Balboa (2009) stated that this perceived position of moral superiority "has been criticised, resisted and rejected" (p. 452). Such resistance has not gone unnoticed by researchers and scholars within PETE, where there have been calls for more integrating and conciliatory perspectives (Ennis, 1997; Sicilia-Camacho \& Fernandez-Balboa, 2009; Tinning, 2002). This perspective, Ennis (1997) continued, enables teachers to feel capable and competent-not alienated-when implementing CP. Similarly, Tinning's (2002) call for a more "modest" approach to this concern suggests that implementation of CP within PETE may require significant rethinking if it is to meet its intended aims and become widely accepted in practice. Similarly, Sicilia-Camacho and Fernandez-Balboa (2009) suggested that those whose intend to promote CP may consider doing so in a less universalizing and imposing manner,

in a way that, far from preaching universalizing principles and imposing 'liberating' prescriptions and seeing people as objects to be liberated, recognizes people as ethical beings capable of reflecting on, deciding about and participating in, the construction of their own identity and their world. (p. 452)

Despite the introduction and subsequent revision of a more socially just and critically conscious health and PE curriculum in Aotearoa New Zealand, evidence and commentary in the literature indicates that the pedagogical approaches of physical educators 
in schools generally do not reflect those principles and objectives originally intended by curriculum writers in New Zealand (Culpan, 2008). This critique appears to be founded on the premise that intended curriculum outcomes should reflect the espoused philosophical nature of the subject-based curriculum and broader curriculum (i.e., national) that guides the subject area. Furthermore, it appears that teachers face a requirement to appropriately align epistemological choices with pedagogical decisions. As Kirk (2005) suggested, "although this sounds like common sense ... [and] although it makes perfect sense, it is not at all common" (p. 213).

This apparent inability of PE teachers in New Zealand to align curricular aims with appropriate epistemological decisions and pedagogical strategies has the authors pondering the possibilities of models-based practice (MBP) within a critically oriented curriculum and associated PETE program. These possibilities may indeed enable PE teachers and PETE students to consider a more conciliatory and modest approach to CP (Tinning, 2002) and indeed begin to activate their own sense of agency (Sicilia-Camacho \& Fernandez-Balboa, 2009).

\section{Models-Based Practice}

Kirk (2013) wrote,

A models-based approach has been advocated as a means of overcoming the serious limitations of the traditional approach to physical education. One of the difficulties with this approach is that physical educators have sought to use it to achieve diverse and sometimes competing educational benefits, and these wide-ranging aspirations are rarely if ever achieved. Models-based practice offers a possible resolution to these problems by limiting the range of learning outcomes, subject matter and teaching strategies appropriate to each pedagogical model and thus the arguments that can be used for educational value. (p. 973)

In a special edition of the Journal of Teaching in Physical Education, Dyson, Kulinna, and Metzler (2016) clarified that MBP can be applied on two levels-superordinate and instructional. The superordinate level includes curriculum, when a PE program staff, 
district policy makers, or national educational authorities choose to define the overarching goals, structures, and content for school programs. At the instructional level, MBP is also applied at the level of the instructional units taught and learned in those curriculums. At the instructional level, teachers make decisions to design, implement, and assess short-term student learning opportunities and their commensurate educational outcomes. The study described here includes the superordinate and instructional levels of MBP, as described by Dyson, Kulinna, and Metzler (2016), as it is strongly contextualized in the NZC and also reflected in a well-defined instructional and pedagogical plan within this curriculum (Ministry of Education, 2007).

Historically, Kirk (2005) and Metzler (2011) proposed that at the instructional level, when implemented effectively, MBP may offer a good way of aligning teaching and learning assumptions, curricular aims, and pedagogical strategies with specific learning objectives in PE. For example, instructional models for PE include Teaching Games for Understanding (Bunker \& Thorpe, 1982), Sport Education (Siedentop, 1994), Teaching Personal and Social Responsibility (Hellison, 2011), and Cooperative Learning (Dyson \& Casey, 2016). These instructional models include more holistic educative perspectives that include the development of cognitive, affective, and moral skills alongside the traditionally privileged performance skills. In this case, effective implementation of these models requires and encourages teachers to work collaboratively with students as a result of implementing constructivist-based learning environments.

In this constructivist view, $\mathrm{PE}$ teachers (re)consider the traditional power relationship evident in educational contexts, where the teacher controls and monitors the learning, and move to one where students are empowered to plot, monitor, and gain greater ownership and direction of their own learning. Constructivist notions of teaching and learning appear to align with the holistic and emancipatory educational aims of CP, as it is suggested in the NZC, where there is a need for provision of educational environments that allow for critical thinking, questioning, and discussion in a power-neutral classroom (Culpan \& Bruce, 2007; Macdonald, 2003; Ministry of Education, 2007). However, as Culpan (2008) in New Zealand, and Curtner-Smith (1999) and Kirk (2005) suggested 
from an international perpsective, physical educators have made some use of MBP and constructivist pedagogy; however, more often than not they default to direct instruction alone, with an emphasis on sport skill development.

The Journal of Teaching in Physical Education (2016, Vol. 35, Issue 4) devoted a special edition to discuss and debate the merits of MBP across a range of countries and contexts. At superordinate and instructional levels, the models discussed included Health Optimizing Physical Education (Dudley, Goodyear, \& Baxter, 2016), Cooperative Learning (Dyson, Colby, \& Barratt, 2016), Personal and Social Responsibility (Gordon, Jacobs, \& Wright, 2016), Sport Education (Hastie \& Wallhead, 2016), Tactical Games (Harvey \& Pill, 2016), and Outdoor and Adventure Education (Sutherland \& Legge, 2016). It appears that while the use of MBP in PE contexts appears to have challenged physical educators in the past, there appear to be a resurgence and growing interest, particularly from academics, in the possibilities of MBP in PE. This has provided the authors with a valuable reminder and further insight into the possibilities for the use of MBP, particularly within the context of a critically oriented PETE program that seeks to graduate knowledgeable and competent PE teachers in Aotearoa New Zealand.

The genesis of this paper originates from a research study looking to investigate the beliefs of a cohort of PETE students nearing graduation after having recently completed a 4-year critically oriented PETE program in New Zealand. The research question asked, what are the graduating PETE students' beliefs about $\mathrm{CP}$ and the pedagogical strategies required to implement HPE within the NZC?

With the above discussion in mind, this paper discusses the findings of this study in light of the literature related to critically oriented PETE programs, the NZC, and the possibilities that MBP may provide in this space.

\section{Method}

\section{The Research Setting: The Critically Oriented PETE Program}

The participants were enrolled in the 4-year critically oriented PETE program. Staff and official program documentation (College of Education, 2014) espouse a socio-critically oriented philosophy and an accompanying constructivist, student-centered approach. 
The program's underpinning philosophy emphasizes emancipatory and transformative pedagogies (i.e., CP) that align with the successful implementation of the NZC. The PETE program is physically and philosophically located within the College of Education, which has recently merged with the university.

The PETE program is a 4-year, professionally-focused Initial Teacher Education program integrating courses in PE pedagogy, sport and exercise science, sociology of sport and PE, and studies in professional practice. Students are required over the 4 years to complete 24 weeks of teaching practice in primary and secondary schools. Students must also pursue broader studies in education, health education, outdoor education, and an additional subject of their choice (College of Education, 2014, p. 21). Upon graduation, students gain provisional teacher registration and are qualified to teach PE and their chosen subject in New Zealand secondary schools (College of Education, 2014).

The underpinning philosophy and content of the PETE program at the heart of this study reflect a critical orientation (see Fyall, 2017, for a more elaborate description). The program emphasizes empowering preservice PE teachers to challenge epistemological and pedagogical assumptions that are taken for granted and, important, to locate and problematize this within a social, historical, and political educational context (Curtner-Smith, 2007; Macdonald \& Brooker, 1999; Tinning 2002, 2010). In New Zealand, such programs aim to produce teachers with a socially critical perspective who are capable of teaching within a CP. In this sense, the courses in pedagogy and sociology become important, as course content and pedagogies emphasize critical theory and $\mathrm{CP}$, and constructivist, student-centered perspectives of teaching and learning. These courses are considered pivotal in the deconstruction and any subsequent reconstruction of the taken-for-granted assumptions that many students have when entering PETE programs (Curtner-Smith, 2007; O'Sullivan, 2005). Courses in sociology explore concepts such as functional theory, critical theory, humanism, and postmodern notions of education, and the relationship of these to the philosophy of the NZC. The pedagogy courses focus on a range of theoretical perspectives of learning and seek to align these perspectives of learning with appropriate pedagogical models and teaching styles. (For 
further detail, examples of these include Mosstons's Spectrum of Teaching Styles, Mosston \& Ashworth, 2002; Cooperative Learning, Dyson \& Casey, 2016; Peer Teaching, Metzler, 2011; Experiential Learning, Kolb, 2015; and an array of games-based teaching models such as Teaching Games for Understanding, Bunker \& Thorpe, 1982; Game Sense, Light, 2013; and play-teach-play, Graham, 2008.) Course content is promoted through a combination of lectures and practical workshops where students are required to "micro-teach" and critically reflect on their ability to conceptualize and implement the course content.

\section{Participants}

In this case study research, voluntary participation was offered to all 32 members of a graduating year cohort from a critically oriented PETE program in Aotearoa New Zealand. As a consequence, 28 students agreed to participate. Purposeful sampling was then employed and nine information-rich cases who represented a "typical” Year 4 student cohort were sought (Gratton \& Jones, 2004). A typical Year 4 student cohort reflected the following: gender (55\% female, $45 \%$ male), an average age of 22.9 years, and an ethnicity makeup of $90 \%$ New Zealand European and 10\% Maori or Pasifika origin. This resulted in four male and five female participants, with an average age of 23.1 years $(S D=1.4)$, being invited to participate in the study. Seven of the nine participants were of New Zealand European origin, one identified as being New Zealand Maori, and the other as Pasifika descent (See Table 1 for demographic details of the participants).

\section{Table 1}

Demographic Information for the Nine Case Study Interview Participants

\begin{tabular}{lllc}
\hline Participant & Gender & Ethnicity & Age (years) \\
\hline Pauline & Female & NZ European & 23 \\
Brigid & Female & NZ European & 23 \\
Emily & Female & NZ European & 22 \\
Candice & Female & NZ European & 22 \\
Alice & Female & Pasifika & 22 \\
Graeme & Male & NZ/Maori & 23
\end{tabular}


Table 1 (cont.)

\begin{tabular}{lllc}
\hline Participant & Gender & Ethnicity & Age (years) \\
\hline Andrew & Male & NZ European & 23 \\
John & Male & NZ European & 27 \\
Robert & Male & NZ European & 23 \\
\hline
\end{tabular}

Note. Mean age of participants $23.1(S D=1.4)$.

\section{Ethical Considerations}

The study was reviewed and approved by the appropriate ethical committee at the university. Consent to participate was gained on a voluntary basis from each participant. The interviews were conducted by the lead author, and the participants were known to the researcher. However, cognizant of considerations of power, gender, race, culture, religion, and class, and the implications of these during the research process, the researcher consequently adopted an inclusive, empowering and empathetic framework (Mutch, 2005). With this in mind, the researcher maintained confidentiality of the interview participants throughout the process, and this paper uses pseudonyms when identifying and reporting the interview data (Mutch, 2005).

\section{Data Collection}

This research employed a semistructured interview method commonly engaged in by educational researchers (Cohen, Manion, \& Morrison, 2007). The main purpose of the interview was to gain an in-depth understanding of the participating students' perspectives, beliefs, and experiences in an environment where they felt at ease to express their understanding in their own terms (Gay, Mills, \& Airasian, 2009).

Preceding the interviews, a semistructured interview schedule was developed and piloted with three students from a different year group. Feedback resulted in some minor adjustments to the schedule mainly to reduce repetitiveness (Gay et al., 2009). A guiding interview schedule of seven questions resulted and was used for each interview. This enabled the researcher to ask each participant "the same basic questions in the same basic order" (Cohen et al., 2007, p. 353), but allow flexibility as the conversation evolved. Table 2 shows the interview questions. 


\section{Table 2}

Semistructured Interview Question Schedule

1. What do you believe HPE within the NZC is all about? What is its philosophy and what is it trying to achieve? Can you identify and explain any course experiences or practicum examples that clarify your beliefs?

2. What is critical theory and how does this relate to critical pedagogy within HPE in the NZC?

3. What do you believe are the pedagogical (teaching) approaches that best suit and are consistent with implementing critical pedagogy and HPE in the NZC?

4. How does humanistic theory embed itself in HPE in the NZC and what does this look like in your teaching?

5. Can you identify and explain any course experiences or practicum examples that clarify your beliefs about these pedagogical (teaching) approaches?

6. How does your knowledge of learning theory (or how knowledge is constructed - epistemology) influence your pedagogical decision?

7. Can you identify and explain any course experiences or practicum examples that clarify your beliefs about these epistemological beliefs (understanding about how people learn) and how you consider this when you consider your teaching approach or pedagogical choice?

The interviews followed the conventional sequence-a personal introduction, a statement assuring the confidentiality of the interview, and double-checking the student's permission to have the interview audio taped. Each interview was recorded digitally for accuracy and lasted between $45 \mathrm{~min}$ and $1 \mathrm{hr}$, enabling the researcher to replay and improve the quality of the transcripts (Silverman, 2006). After the interview data were transcribed verbatim, member checks were conducted where participants were sent electronic versions of the transcripts and asked to validate the accuracy. All participants were comfortable with the original transcripts being used for the analysis phase of the study. Information for each interview participant was then included in the thematic analysis and resulting reporting of the data. 


\section{Data Analysis}

Data generated from the semistructured interviews were analyzed and reoccurring themes identified and explored (Mutch, 2005). The answers to each interview question from all nine participants were grouped, and then through constant comparison and inductive analysis, key themes began to emerge (Denzin \& Lincoln, 2005). This process of analysis was aided by Rossman and Rallis' (1998) coding system, where text information from each transcript and from each question were categorized according to the frequency of reoccurring words or phrases. This coding system enabled a systematic analysis and reduction of the data to a number of smaller identifiable and discrete categories (Rossman \& Rallis, 1998).

The final decision on a theme was considered and only determined if at least seven of the nine participants articulated the coded theme. Initially, the data analysis reflected three major themes: (1) Movement and the Multiple Aims of Health and Physical Education, (2) HPE in the NZC: An Area of Paradigmatic Uncertainty, and, (3) The Teaching Continuum and Moving Beyond Direct Instruction. However, further analysis and coding revealed two subthemes within the second major theme, HPE in the NZC: An Area of Paradigmatic Uncertainty. Specifically, these subthemes have been titled Critical Theory and Critical Pedagogy as Challenging Inequality and also Humanism: Complexity or Confusion? These three major themes, and two subthemes, are outlined in the Findings section and further elaborated in the Discussion section.

\section{Findings}

This section reports the findings from the analysis of the interview data, reflecting the key themes, and further discusses these in light of the expressed research question and the literature relating to critically oriented PETE programs and MBP.

\section{Movement and the Multiple Aims of Health and Physical Education}

The evidence presented by the participants suggests they were developing a broader definition of health and PE, as promoted in the PETE program at the center of the study and that supported and promoted the NZC's multiple aims and objectives. Indeed, the participants saw, for example, a need for their students to consider and 
enhance personal and social relationships extending into societal and cultural settings and therefore create the conditions that promote the well-being of self, others, and society.

It's looking at ways they can be more active, not just ... . [physically] active but in relationships and also the wider community ... perhaps helping others to live healthy and active lifestyles. (Andrew)

The most notable discourse that emerged in this theme was that the participants believed that movement and activity were an important context for learning and implementing the NZC objectivestherefore, an important aspect for teachers to consider in their pedagogical choices. Graeme's response reflects this well:

Well I'm a great believer that Physical Education is a great tool that allows us to use movement for our lessons. So in terms of PE we can use movement and get outdoors and you know we can teach those principles and values and especially the vision of the curriculum document in such a unique way that others [curriculum areas] can't. Then also by using movement, $[\mathrm{PE}]$ is about how it can implement interpersonal skills, you know, how it can implement relationships with society, within the school communities. The underpinning philosophy for me is that we've got movement to use. I think these things can be more easily achieved . . . very easily implemented through the uniqueness of sport and PE.

Similarly, all the other participants referred to "movement" (consisting of a variety of movement-related contexts, such as sport, outdoor education activities, recreational activities, and dance) as being the key context for learning within the NZC. This was constantly referred to throughout the interviews. Pauline, for example, referred to the physical context as an overarching term:

It's Physical Education, [we] learn to relate to other people, manage themselves with, like, inter-personal skills and stuff, all within the physical context, yeah I reckon movement, like sports and dance and outdoor recreation and being involved physically is really important for learning in PE. 
Further analysis suggested that while this broad definition could be articulated, there was little evidence to suggest how this could be specifically enacted in the classroom, particularly "in, through and about" movement. This reaffirms some of the critique of the draft HPENZC, where leading up to and continuing after its release many suggested that the enormity of change posed by HPENZC and its subsequent revision, the NZC, presented many challenges for PE teachers, PETE program staff, and their students in New Zealand (Barker, 2008; Burrows \& Ross, 2003; Culpan, 2008; EF, 1998).

\section{HPE in the NZC: An Area of Paradigmatic Uncertainty}

Subsequent interview questions explored the concepts of critical theory, CP, and humanism in relation to HPE within the NZC. Participants were asked to define and discuss how these concepts are embedded in HPE in the NZC. Additionally, participants were asked to draw on course and practicum experiences, which promoted these concepts, to further articulate their understanding and implementation of these concepts in practice.

\section{Critical Theory and Critical Pedagogy as Challenging Inequality}

All of the participants keenly responded to Questions 2 and 3 related to their perceptions of critical theory and its alignment to CP. However, although their responses were expressed in a number of ways, these questions resulted in one unanimous subtheme. In this instance, all of the participants saw $\mathrm{CP}$, and its underpinning critical theory, as a way of challenging inequality. The following interview excerpts reflect this theme well. Alice, for example, saw critical theory as an examination of those who are advantaged and those who are disadvantaged:

Who's advantaged, who's disadvantaged and why and that kind of stuff. When I hear the word "critical" I automatically think about critical thinking, critical views, you are looking at both sides. I also see like critical theory as critically analyzing something, looking at both sides of the fence. And you know for people to be able to see it from both sides of the fence and not look at it from just the top layer really and go down deeper and critically look at it, the positives, negatives, advantages, disadvantages. 
When asked to consider his teaching practicum experience and relate this to $\mathrm{CP}$, Robert was not specific, but he stated:

I think it's around health and wellbeing and it was all around critical thinking, critical knowledge ... you know, it allowed them [students] to look at both sides on the fence, to really go deeper ... [to] come up with debate, I allowed them to think. You don't have to agree with it ... they had to critically think themselves, with shared learning, think about it and delve deeper yeah.

Andrew, who believed he understood things well, contributed the idea that exploring power and hegemony may play a part in $\mathrm{CP}$ and the overall philosophy of HPE:

I think I've got a good grasp of that, like it took me some time to understand it but just this year doing socio-cultural aspects of Physical Education I think I've gained a much better understanding of that. I think it's important to incorporate that into my teaching, that is, one thing I think is important. So, just looking at things from a much wider perspective. Looking at who's advantaged, who is disadvantaged and the sort of balances of power and hegemonic relationships and all sorts of things.

When asked to give examples, he continued the theme of advantaged versus disadvantaged and expressed the difficulty in implementing this in his teaching practicum classes:

Looking at who's advantaged and who is disadvantaged ... Yeah I think it's quite hard to incorporate it sometimes you need to know your students quite well cause it's deeper like even myself I've found it hard sometimes to think of things critically ... to critically think. (Andrew)

All the participants stopped short of utilizing critical theory, defining CP as it is intended in HPE in the NZC and as it was promoted in the program content. It appeared that the participants were only beginning to grapple with the notion of critical theory and had limited or no knowledge of its application to CP. Analysis revealed that participants' beliefs around critical theory were limited and their 
understanding appeared superficial. The participants believed that critical theory embedded itself in wider societal issues, in essence, as a topic for discussion. Brigid's interview excerpt reflects this common position by all nine participants:

So, like critical pedagogy, on TP [Teaching Practicum] we looked at the rules of sport and applied the ethics associated with that ... (pause) ... so being able to look at both sides of it and not just one side and making sure that no one is unfairly advantaged.

\section{Humanism: Complexity or Confusion?}

Further interview questions explored the concept of humanism, the second paradigmatic concept underpinning HPE in the NZC and embedded in the NZC philosophy. The researcher's field notes reflected that their articulations were often fragmented and the participants would often stop mid-sentence and begin on a different line of discussion. All of the participants, despite prompting from the interviewer to draw on their practicum experiences, struggled to offer substantial information around humanism and its relationship to PE in the NZC. Candice, who appeared the least confident of the participants, offered,

Uumm, humanism is like humans so I guess like people and relating to people and, uumm (pause), humanistic values I don't know (sigh, pause) ... I just don't know (sigh).

Brigid, who with previous questions had been very free to converse and "think out loud," took a different approach to this question and appeared to be less keen and sure of herself. She replied,

When I think of it just logically, I'd say Humanism would be, uumm, relating well to others totally off topic, uumm, no, I'm stuck... (pause).

Similarly, Emily also struggled to articulate any meaningful definition and appeared to be unsure of her response. When questioned, she stated, 
Oh ah, testing my brain. Uumm, humanism, uumm ... (pause)... what to do with people and, uumm ... (pause)... how people perceive ideas and how they, uumm ... (pause)... I guess how they, uumm, interact and display them, I guess?

When prompted to reflect on her teaching practice experiences to enhance this definition, Emily responded, but continued to be unconfident in her reply:

Argh, how would I see that in PE? Uumm, I think the interaction thing is a big thing in Physical Education, not just between individual teacher and student, but between student to student, groups of students with teacher in the classroom, and with other staff, other people involved, uumm, and I guess it's, uumm aahh, I suppose I think Physical Education has placed quite a lot on it, you know, they, it's all about working with people, interacting with people or being a person and being involved and interacting ... (pause)... I guess?

Unlike the descriptions and definitions given for critical theory, where the students were confident in expressing their views, albeit with limited insight, the students appeared to struggle with the concept of humanism and had much difficulty defining it, let alone articulating their ability to enact it when teaching.

\section{The Teaching Continuum and Moving Beyond Direct Instruction}

The common belief held by the participants reflected that a variety of pedagogical strategies may be required for implementing HPE in the NZC. Analysis also suggested that the participants were describing a continuum of teaching styles, consisting of a teacher-centered approach at one end and a learner-centered approach at the other. It also became apparent that in describing this continuum, the participants saw merit in teachers shifting between the direct teacher-centered approaches and more facilitative student-centered approaches. The following vignettes encapsulate this theme where the participants believed that a variety of learning contexts were required and an accompanying variety of teaching styles were required to meet these contexts. 
It just depends on the class, like, if the class is quite capable of working by themselves, then for some reason I don't need to directly teach them anything and they can do it themselves then. I can put them into group work and they can go and, you know, TGfU, inquiry-based sort of stuff; otherwise, if I need to tell them something I'll tell them (pause) it just all depends. (Pauline)

When asked to draw on her course or practicum experiences to elaborate further in this area, Alice added,

Oh yeah, I used many different contexts and different teaching styles. I remember using a dance context where I had them working in groups, working together. I did a stomp class and split the class into groups and wanted to see if it would work. I gave them an outline and they investigated group dynamics and all that kind of stuff, so I don't know, sometimes it doesn't always work, but I think it's something, as a teacher, I believe you need to learn to do ... (pause) ... through group work, or like stuff outside the classroom, or just whatever fits the class, uumm, teaching might be teacher directed if needed or student led if needed.

Robert began to describe varieties of indirect pedagogical approaches and again justify his belief that teachers can draw from a number of different pedagogical approaches and instructional models. As is evidenced in the following quote, such decisions depend entirely on the needs and characteristics of the learners, or as he stated, the "type of kids and what you are teaching":

(pause) ... Uumm specific examples, I don't know, I guess doing things in groups or doing tasks individually, doing in pairs, cooperatively, working as a whole class, having discussions or play-teach-play stuff works. I think I mean depending on what type of kids and what you are teaching, you could probably use all different styles ... (pause) ... but like I said, it depends on the situation. Usually, I try and steer away from drills, uumm, I find them boring. If it was something I wanted them to learn, it would possibly be some sort of activity or game. Yeah, I think so long as the information 
is getting put across, the teacher becomes more facilitative. You're not quite so important in their learning at that stage. I think it's important for the students to actually have the opportunity to learn themselves ... so it's more independent because it's their learning and their understanding. If it's not their understanding, they're not going to learn.

Commonly, the participants eluded to "different ways of teaching" and articulated these to learning theory. For example, Emily quoted,

... If I am being direct and behaviorist, you know, learning skills and rewarding positive behavior modification and using positive reinforcement. Alternatively, depending on what you are doing, students might get more of an understanding of something as a result of learning through constructivism, like TGfU and experiential learning, cooperative learning and group work, inquiry stuff, you know, so they can link old information to new and build on it.

It appears that the case study participants believed that pedagogical processes could be placed on a continuum. At one end of the continuum lay a teacher-centered approach where decisions around learning contexts and content were firmly in the hands of the teacher. At the other end of the continuum lay the student-centered approach where control over and power to make such decisions shifts to the students. Epistemologically, the participants' unanimously believed that the teacher-centered approach has epistemological origins in behaviorist discourse. Conversely, the student-centered approach, was unanimously supported as emanating from constructivist learning theory. It appeared that all participants believed that successful implementation of HPE within the NZC involved a knowledge and implementation of a variety of teaching styles and instructional models based on knowledge of learning theory. Furthermore, any decisions on the appropriate teaching style or instructional model should be determined by the characteristics of the students and the content being taught. The participants also added that where possible, learner-centered, constructivist pedagogical approaches should be favored, as these were more in line with curriculum aims 
and the characteristics, needs, and assumptions of contemporary 21 st century students.

\section{Discussion}

Based on these findings, several conclusions may be drawn from this study. First, the participants beliefs and behaviors were likely influenced by the content, pedagogies, and experiences within the 4 -year PETE program. The program may have encouraged the participants to explore personal philosophical positions and question particular decisions regarding their personal beliefs about PE. The net effect of this meant that the participating PETE students had begun to dissect and evolve their previous conceptualization of PE and PE teaching. Specifically, the nine participants saw, to varying extents, the underpinning philosophy of the curriculum as having multiple aims, where, through a variety of contexts, not exclusively sport, students can learn and consider this knowledge from a personal, social, and societal perspective.

Stothart (2000) suggested that while sport is firmly entrenched within New Zealand culture and historically has a firm place within PE contexts, sport and PE should not be considered synonymously. The participants confirmed Stothart's view by expressing that HPE in the NZC has multiple aims and objectives and requires a variety of movement contexts for successful teaching and learning to occur. The participants comments demonstrated consistency with the NZC intentions, where the contexts for learning are stated as "play, games, sport, exercise, recreation, adventure, and expressive movement in diverse physical and social environments" (Ministry of Education, 2007, p. 23). Therefore, consistent with the critical and humanistic aims and intentions of the NZC, the participants' beliefs suggested that they had a clear understanding that the HPE curriculum philosophy extends beyond the traditional sport performance discourse.

At face value, the participants understanding of the multiple aims and objectives may appear to connect philosophical theory with practice, and to some extent it does; however, it is suggested that the participants were still grappling with the theory. The study findings suggest that the participants may still have some way to go before they can include and reflect such thinking into their practice. This appears to be, in part, due to a lack of knowledge, lack of 
understanding, and confusion around the philosophical underpinnings of the HPE learning area.

Specifically, one source of confusion lay in the participants' apparent inability to articulate and conceptualize humanistic philosophy as it relates to the NZC. They could articulate an understanding of holism and need to holistically educate their students, but this appeared superficial at best. This articulation fell short of conceptualizing humanistic education as a means of comparing and contrasting the traditional, dominant skill performance model with the humanistic, holistic view of education as proposed in the NZC.

According to Culpan and Bruce (2007) and Gillespie and Culpan (2000), a humanistic curriculum that is wide ranging and extends beyond the traditional sport performance discourse, such as the NZC, requires PETE programs to develop, implement, and model pedagogical approaches that are humanistic and critical in nature. These pedagogical approaches should therefore reflect the capacity for promoting independence, positive self-direction, curiosity, and creativity for the learner. Learning is promoted through inquiry and discovery and ultimately leads to the holistic development of the learner (e.g., physical, cognitive, affective, and moral domains of learning). Therefore, accompanying teaching approaches should be constructivist and learner-centered in their epistemological justification and applied in, through, and about movement (Culpan, 2004).

Another area of concern to the authors was reflected in the participants' lack of knowledge and understanding around critical theory and its application to CP. The participants believed that critical theory embedded itself in wider societal issues, in essence, as a topic for discussion. Drawing on the work of Apple (2004), the authors propose that these topics or issues have evolved from those involving class, the economy, and the state and include "issues of sexuality and the body, disability, post colonialism and many more" (Apple, 2004, p. 187). However, Apple (2004) continues to suggest that unlike the participants in this study, critical pedagogues should seek to challenge the very nature of the systems and structures they are a part of and seek to change the dominant conservative culture and epistemology associated with many educational settings (Apple, 2004). However, despite much prompting and attempts by the interviewer to consider and relate these considerations to their 
own teaching and learning experiences, and to indeed "challenge" the "dominant conservative culture" and epistemology, the students struggled to appropriately define critical theory and make the appropriate connections to their own epistemological beliefs.

The authors suggest that this may, in no small part, be attributed to the PETE programs inability to inform and equip the participants with appropriate knowledge around critical theory and CP. Despite the espoused "critically oriented" philosophy of the program, and the emphasis on criticality within the pedagogy and sociology courses, it appears that the participants were still struggling to make appropriate adjustments and connections. This apparent lack of content and curriculum knowledge, suggested by the participants, may have implications for critically oriented PETE programs in New Zealand and internationally.

The authors propose that neophyte PETE students and early career PE teachers may be subjected to political manipulation, as this lack of content knowledge may "open the way" for an apprenticeship model of learning (Lave \& Wenger 1991). In this sense, the learner is subordinated to established practices where empowerment and change may only be possible through achievement of compatibility with and confidence in established practices. While the apprenticeship model of learning may emphasize the importance of ensuring culture and context receive recognition in educational contexts, it does not bring into question the epistemological assumptions or the associated pedagogical practices evident in PE. Essentially, in the view of the researchers, the apprenticeship model of learning becomes problematic in introducing a curriculum underpinned by differing paradigmatic assumptions, if PETE students must align pedagogical practices with epistemological beliefs and a variety of learning outcomes. Fundamentally, this theory to practice nexus may require greater scrutiny by those charged with deciding on curriculum and pedagogical knowledge presented in critical PETE programs.

However, given these concerns, the majority of participants demonstrated an understanding and application of behaviorist and constructivist teaching approaches. In conceptualizing a teaching continuum consisting of teacher-centeredness at one end and student-centeredness at the other, the participants believed that by 
aligning learning theory and a variety of teaching styles, with an appropriate instructional model they could effectively teach and implement the NZC. Depending on the nature of the students and the content involved, the teacher could, in the best interests of the students, make a decision around the best approach to choose.

This appears consistent with the many cogent arguments that MBP presents a sound rationale for aligning and implementing curriculum objectives and aims (e.g., see Kirk, 2006; Metzler, 2011). When considering $\mathrm{CP}$, and therefore the emancipatory concerns of the NZC, PE teachers need to enact learner-centered, constructivist pedagogies on a teacher-centered/student-centered continuum. Therefore, when choosing an instructional model, PE teachers in New Zealand should align curriculum learning objectives and learning theory with the appropriate instructional model. That is, to educate critically and humanistically, they would need to choose instructional practices close to the learner-centered end of the continuum and select an instructional model, or models, founded on similar epistemology. On the other hand, direct instruction-based models would shift toward the teacher-centered end of the continuum when the teacher considered that the learner-required scaffolding.

According to van Nieuwerburgh (2010), knowledge of a variety of teaching approaches (and the authors would suggest "aligned" instructional models) has merit. He further suggested that in this way, $\mathrm{PE}$ teachers could move to a genuinely learner-centered approach by the fact that pedagogical decisions would be based on the best interests of the learner (van Nieuwerburgh, 2010). Adopting such a continuum approach to student-centered teaching and learning may support the assertion that humanistic and learner-centered practices may be appropriate in some situations, but in others, however, it may be more supportive to be more directive. For example, if the need is to develop independent thinking, self-esteem, or self-confidence, the teacher and perhaps the student would agree to use a more learner-centered approach. On the other hand, if the learner requires new skills or additional information, the teacher may employ a more directive approach. This could be interpreted as being learner centered in that the best interests of the student are being addressed as the professional knowledge and experience of the teacher enables and ironically empowers them to make such decisions. 
A continuum approach appears to have resonance with the EF (1998), which voiced significant critique around the draft HPENZC. In the EF's (1998) view, teachers, who are considered authorities in both "content and procedures," are professionally equipped to identify individual learning needs and task requirements. Therefore, in the best interests of the student, the notion of student-centeredness relies on the teachers' decisions to align the learners' needs, the content, and the task requirements to an appropriate "style," or "model" as the authors have argued, of teaching.

\section{Concluding Remarks}

This discussion does not seek to be an everythingism with regard to $\mathrm{CP}$, but rather an alternative where PETE students can begin to "... explore their own ethics and activate their own sense of agency" (Sicilia-Camacho \& Fernandez-Balboa, 2009, p. 456). Indeed, the argument presented subscribes more to van Nieuwerburgh's (2010) and the EF's (1998) definitions of student-centeredness, and therefore conflicts with the curriculum architects' definition and subsequent dismissal of the EF's position (Culpan, 2004).

However, given the academic discourse calling for a reasonable and more conciliatory approach to implementing CP (Bain, 1997), and one that modestly (Tinning, 2002) promotes CP as the coming together of critical theory, humanism, and pedagogy (Kincheloe, 2008), the researchers believe that MBP may provide an appropriate vehicle to do so. The researchers believe that this compromise is a beginning point where PETE students can feel more confident and competent when conceptualizing and implementing $\mathrm{CP}$ within the NZC.

\section{References}

Apple, M. W. (2004). Ideology and curriculum (3rd ed.). New York, NY: Routledge Falmer. https://doi.org/10.4324/9780203487563

Bain, L. (1997). Transformation in the postmodern era: A new game plan. In J. M. Fernandez-Balboa (Ed.), Critical postmodernism in human movement, physical education, and sport (pp. 183-195). Albany: State University of New York Press.

Barker, M. (2008). The New Zealand Curriculum and preservice teacher education: Public document, private perceptions. Curriculum Matters, 4, 7-19. 
Bunker, D., \& Thorpe, R. (1982). A model for teaching games in secondary schools. Bulletin of Physical Education, 18(1), 5-8.

Burrows, L. (2005). Do the right thing: Chewing the fat in physical education. Journal of Physical Education New Zealand, 38(1), $7-16$.

Burrows, L., \& Ross, B. (2003). Introduction. In B. Ross \& L. Burrows (Eds.), It takes two feet: Teaching physical education and health in Aotearoa New Zealand (pp. 13-17). Palmerston North, New Zealand: Dunmore Press. https://doi.org/10.31468/cjsdwr.511

Cohen, L., Manion, L., \& Morrison, K. (2007). Research methods in education (6th ed.). London, United Kingdom: Routledge. https://doi.org/10.4324/9780203029053

College of Education. (2014). Bachelor of education (physical education): Initial teacher education qualifications handbook. Christchurch, New Zealand: University of Canterbury Press.

Culpan, I. (2004). Physical education curriculum development: A humanist positioning. In A. M. O’Neill, J. Clark, \& R. Openshaw (Eds.), Reshaping culture, knowledge, and learning: Policy and content in the New Zealand Curriculum framework (pp. 225243). Palmerston North, New Zealand: Dunmore Press.

Culpan, I. (2008). Physical education and the New Zealand curriculum: Maximising the opportunity. Journal of Physical Education New Zealand, 41(3), 51-61.

Culpan, I., \& Bruce, J. (2007). New Zealand physical education and critical pedagogy: Refocusing the curriculum. International Journal of Sport and Health Sciences, 5, 1-11. https://doi. org/10.5432/ijshs.5.1

Curtner-Smith, M. D. (1999). The more things change the more they stay the same: Factors influencing teachers' interpretations and delivery of National Curriculum Physical Education. Sport, Education, and Society, 4(1), 75-97. https://doi.org/ $10.1080 / 1357332990040106$

Curtner-Smith, M. (2007). The impact of critically oriented physical education teacher education on preservice classroom teachers. Journal of Teaching in Physical Education, 26(1), 35-56. https:// doi.org/10.1123/jtpe.26.1.35

Denzin, N. K., \& Lincoln, Y. S. (Eds.). (2005). The Sage handbook of qualitative research (3rd ed.). Thousand Oaks, CA: Sage. 
Dudley, D., Goodyear, V., \& Baxter, D. (2016). Quality and healthoptimizing physical education: Using assessment at the health and education nexus. Journal of Teaching in Physical Education, 35(4), 324-336. https://doi.org/10.1123/jtpe.2016-0075

Dyson,B., \&Casey, A.(2016).Cooperativelearninginphysicaleducation and physical activity: A practical introduction. London, United Kingdom: Routledge. https://doi.org/10.4324/9781315739496

Dyson, B. P., Colby, R., \& Barratt, M. (2016). The co-construction of cooperative learning in physical education with elementary classroom teachers. Journal of Teaching in Physical Education, 35(4), 370-380. https://doi.org/10.1123/jtpe.2016-0119

Dyson, B., Kulinna, P., \& Metzler, M. (2016). Introduction to the special issue: Models based practice in physical education. Journal of Teaching in Physical Education, 35(4), 297-298. https:// doi.org/10.1123/jtpe.2016-0203

The Education Forum. (1998). Health and Physical Education in the New Zealand Curriculum: A submission on the draft. Auckland, New Zealand: Author.

Ennis, C. D. (1997). Defining the dreaded curriculum: Tensions between the modern and the postmodern. In J. M. FernandezBalboa (Ed.), Critical postmodernism in human movement, physical education, and sport (pp. 207-221). Albany: State University of New York Press.

Fernandez-Balboa, J. M. (1997a). Physical education teacher preparation in the postmodern era: Towards a critical pedagogy. In J. M. Fernandez-Balboa (Ed.), Critical postmodernism in human movement, physical education, and sport (pp. 121-138). Albany: State University of New York Press.

Fernandez-Balboa, J. M. (Ed.). (1997b). Critical postmodernism in human movement, physical education, and sport. Albany: State University of New York Press.

Fernandez-Balboa, J. M., Barrett, K., Solomon, M., \& Silverman, S. (1996). Perspectives on content knowledge in physical education. Journal of Physical Education, Recreation, and Dance, 67(9), 54-61. https://doi.org/10.1080/07303084.1996.10604856

Freire, P. (1970). Pedagogy of the oppressed. New York, NY: Herder and Herder.

Fyall, G. (2016). Biomechanics, the health and physical education curriculum, and Confucius? Considerations for teaching, learning, and assessment. Curriculum Matters, 12, 82-108. https://doi.org/10.18296/cm.0015 
Fyall, G. (2017). Graduating physical education student teachers perceptions of a critically oriented HPE curriculum: (Re)constructing constructivist frameworks in PETE. AsiaPacific Journal of Health, Sport, and Physical Education, 8, 211-228. https://doi.org/10.1080/18377122.2017.1345285

Gay, L. R., Mills, G. E., \& Airasian, P. (2009). Educational research: Competencies for analysis and applications (9th ed.). Upper Saddle River, NJ: Pearson Education.

Gillespie, L., \& Culpan, I. (2000). Critical thinking: Ensuring the 'education' aspect is evident in physical education. Journal of Physical Education New Zealand, 33(3), 84-96.

Giroux, H. A. (1983). Theory and resistance in education: A pedagogy for the opposition. South Hadley, MA: Bergin and Garvey.

Gordon, B., Jacobs, J. M., \& Wright, P. M. (2016). Social and emotional learning through a Teaching Personal and Social Responsibility based after-school program for disengaged middle-school boys. Journal of Teaching in Physical Education, 35(4), 358-369. https:// doi.org/10.1123/jtpe.2016-0106

Graham, G. (2008). Teaching children physical education: Becoming a master teacher (3rd ed.). Champaign, IL: Human Kinetics.

Gratton, C., \& Jones, I. (2004). Research methods for sports studies. London, United Kingdom: Routledge.

Gur-Ze'ev, I. (n.d.). Toward a non-repressive critical pedagogy. Retrieved from http://ilangz.edu.haifa.ac.il/research-areas-ofilan/Critical-Pedagogy

Harvey, S., \& Pill, S. (2016). Comparisons of academic researchers' and physical education teachers' perspectives on the utilization of the Tactical Games Model. Journal of Teaching in Physical Education, 35(4), 313-323. https://doi.org/10.1123/jtpe.20160085

Hastie, P. A., \& Wallhead, T. (2016). Models-based practice in physical education: The case for Sport Education. Journal of Teaching in Physical Education, 35(4), 390-399. https://doi.org/10.1123/ jtpe.2016-0092

Hellison, D. R. (2011). Teaching personal and social responsibility through physical activity (3rd ed.). Champaign, IL: Human Kinetics.

Jewett, A. E. (1994). Curriculum theory and research in sport pedagogy. Sport Science Review, 3(1), 56-72. 
Jewett, A. E., Bain, L. L., \& Ennis, C. D. (1995). The curriculum process in physical education (2nd ed.). Dubuque, IA: Brown and Benchmark.

Kincheloe, J. L. (2008). Critical pedagogy primer (2nd ed.). New York, NY: Peter Lang. https://doi.org/10.1007/978-1-4020-8224-5

Kirk, D. (1988). Physical education and curriculum study: A critical introduction. London, United Kingdom: Croom Helm. https:// doi.org/10.1080/0022027880200505

Kirk, D. (2005). Future prospects for Teaching Games for Understanding. In L. L. Griffin \& J. I. Butler (Eds.), Teaching Games for Understanding: Theory, research, and practice (pp. 213227). Champaign, IL: Human Kinetics.

Kirk, D. (2006). Sport Education, critical pedagogy, and learning theory: Towards an intrinsic justification for physical education and youth sport. Quest, 58, 255-264. https://doi.org/10.1080/00 336297.2006.10491882

Kirk, D. (2010) Defining physical education and the possibility of the $\mathrm{id}^{2}$. In D. Kirk (Ed.), Physical education futures (pp. 10-23). Abingdon, United Kingdom: Routledge.

Kirk, D. (2013). Educational value and models-based practice in physical education. Educational Philosophy and Theory, 45(9), 973-986. https://doi.org/10.1080/00131857.2013.785352

Kolb, D. A. (2015). Experiential learning: Experience as the source of learning and development (2nd ed.). Upper Saddle River, NJ: Pearson Education.

Lave, J., \& Wenger, E. (1991). Situated learning: Legitimate peripheral participation. Cambridge, United Kingdom: Cambridge University Press. https://doi.org/10.1017/CBO9780511815355

Lawson, H. (1992). Towards a socioecological conception of health. Quest, 44, 105-121. https://doi.org/10.1080/00336297.1992.104 84044

Light, R. (2013). Game Sense: Pedagogy for performance, participation, and enjoyment. New York, NY: Routledge.

Macdonald, D. (2003). Curriculum change and the postmodern world: Is the school reform project an anachronism? Journal of Curriculum Studies, 35, 139-149. https://doi.org/ 10.1080/00220270210157605

Macdonald, D., \& Brooker, R. (1999). Articulating a critical pedagogy in physical education teacher education. Journal of Sport Pedagogy, 5(1), 51-64. 
McLaren, P. (1995). Critical pedagogy and predatory culture: Oppositional politics in a postmodern era. London, United Kingdom: Routledge.

Metzler, M. W. (2011). Instructional models for physical education (3rd ed.). Scottsdale, AZ: Holcomb Hathaway.

Metzler, M. W., McKenzie, T. L., van der Mars, H., Barrett-Williams, S. L., \& Ellis, R. (2013). Health Optimizing Physical Education (HOPE): A new curriculum for school programs-Part 1: Establishing the need and describing the model. Journal of Physical Education, Recreation, and Dance, 84(4), 41-47. https:// doi.org/10.1080/07303084.2013.773826

Ministry of Education. (1999). Health and physical education in the New Zealand Curriculum. Wellington, New Zealand: Learning Media.

Ministry of Education. (2007). The New Zealand Curriculum. Wellington, New Zealand: Learning Media.

Mosston, M., \& Ashworth, S. (2002). Teaching physical education (5th ed.). San Francisco, CA: B. Cummings.

Mutch, C. (2005). Doing educational research: A practitioner's guide to getting started. Wellington, New Zealand: New Zealand Council for Educational Research.

O'Sullivan, M. (2005). Beliefs of teachers and teacher candidates: Implications for teacher education. In F. C. da Costa, M. Cloes, \& M. Gonzales (Eds.), The art and science in teaching physical education and sport (pp. 149-164). Lisbon, Portugal: Universidade De Technica.

O’Sullivan, M., Siedentop, D., \& Locke, L. F. (1992). Towards collegiality: Competing viewpoints among teacher educators. Quest, 44, 266-280. https://doi.org/10.1080/00336297.1992.104 84054

Philpot, R. (2016). Physical education initial teacher educators' expressions of critical pedagogy(ies): Coherency, complexity, or confusion? European Physical Education Review, 22(2), 260-275. https://doi.org/10.1177/1356336X15603382

Philpot, R., \& Smith, W. (2011). Beginning and graduating studentteachers' beliefs about physical education: A case study. AsianPacific Journal of Health Sport and Physical Education, 2(1), 33-50. https://doi.org/10.1080/18377122.2011.9730342

Rossman, G. B., \& Rallis, S. F. (1998). Learning in the field: An introduction to qualitative research. Thousand Oaks, CA: Sage. 
Sage, G. H. (1993). Sport and physical education and the new world order: Dare we be agents of social change? Quest, 45, 151-164. https://doi.org/10.1080/00336297.1993.10484081

Sicilia-Camacho, A., \& Fernandez-Balboa, J. M. (2009). Reflecting on the moral bases of critical pedagogy in PETE: Towards a Foucaultian perspective on ethics and the care of the self. Sport, Education, and Society, 14(4), 443-463. https://doi. org/10.1080/13573320903217166

Siedentop, D. (1994). Sport education: Quality PE through positive sport experiences. Champaign, IL: Human Kinetics.

Siedentop, D., \& Tannehill, D. (2000). Developing teaching skills in physical education (4th ed.). Mountain View, CA: Mayfield.

Silverman, D. (2006). Interpreting qualitative data: Methods for analyzing talk, text, and interaction. London, United Kingdom: Sage.

Stothart, B. (2000). Uncomfortable bedfellows: Sport and physical education, a problematic relationship. Journal of Physical Education New Zealand, 33(1), 40.

Sutherland, S., \& Legge, M. (2016). The possibilities of "doing" outdoor and/or adventure education in physical education/ teacher education. Journal of Teaching in Physical Education, 35(4), 299-312. https://doi.org/10.1123/jtpe.2016-0161

Tinning, R. (1991). Teacher education pedagogy: Dominant discourses and the process of problem setting. Journal of Teaching in Physical Education, 11(2), 1-20. https://doi.org/10.1123/jtpe. 11.1.1

Tinning, R. (2002). Towards a 'modest' pedagogy: Reflections on the problematics of critical pedagogy. Quest, 54, 224-240. https:// doi.org/10.1080/00336297.2002.10491776

Tinning, R. (2010). Pedagogy and human movement: Theory, practice, research. London, United Kingdom: Routledge.

van Holst, A. (1993). Planning physical education with intent: A personal meaning approach. CAHPER Journal de l'ACSEPL, 1993, 15-17.

van Nieuwerburgh, C. (2010). Holism in sports coaching: Beyond humanistic psychology-A commentary. International Journal of Sports Science and Coaching, 5(4), 463-464. https://doi. org/10.1260/1747-9541.5.4.439 
Copyright of Physical Educator is the property of Sagamore Publishing and its content may not be copied or emailed to multiple sites or posted to a listserv without the copyright holder's express written permission. However, users may print, download, or email articles for individual use. 